\title{
El campo literario de la ciencia ficción en Costa Rica: una mirada a la polémica por la fijación de su canon
}

Por: Lic. Ronald Sáenz Leandro', Universidad de Costa Rica, Costa Rica

ORCID: 0000-0001-8717-1870

Recibido: 30 de enero, 2019.

Aceptado: 21 de octubre, 2019.

\section{RESUMEN}

El presente trabajo brinda una mirada panorámica sobre la polémica de la literatura de ciencia ficción en Costa Rica, misma que hasta la fecha no ha sido estudiada por la crítica. Parte de los conceptos de "campo literario" y "canon", para posteriormente presentar una síntesis de los principales argumentos y actores que tienen lugar en esta polémica literaria. Finalmente, reflexiona en torno a la manera en que se inscribe dentro de la lucha por el establecimiento de una determinada propuesta creativa, en el intento de fijar un canon literario para la ciencia ficción producida en este país.

\section{ABSTRACT}

\section{The literary field of science fiction in Costa Rica: a look at controversy by} the fixation of its canon

This work provides an overview of the controversy of science fiction literature in Costa Rica, which, to date, has not been studied by critics. It starts from the concepts of literary field and canon, then offers a synthesis of the main arguments and actors involved in this literary polemic. Finally, it reflects on its participation in the struggle for the establishment of a specific creative proposal in the attempt to set a literary canon for science fiction in Costa Rica.

Los adscritos a los trabajos [de ciencia ficción] discuten sobre la ortodoxia de un argumento, sobre el respeto a la verosimilitud científica y fantacientífica, con el puntilloso dogmatismo de los retóricos medievales y renacentistas.

Umberto Eco, Apocalípticos e Integrados

1 Licenciado en Ciencias Políticas, graduado de la Universidad de Costa Rica, y maestrando del Programa Académico en Literatura Latinoamericana, en esa misma casa de estudios. Labora como docente, también en la Universidad de Costa Rica. Contacto: ronald.saenz@ ucr.ac.cr.
Ronald Sáenz Leandro. El campo literario de la ciencia ficción en Costa Rica: una mirada a la polémica por la fijación de su canon. Revista Comunicación. Año 40, volumen 28, número 2, julio-diciembre, 2019. Instituto Tecnológico de Costa Rica. ISSN: 0379-3974 / e-ISSN1659-3820.
PALABRAS CLAVE:

canon literario, campo literario, ciencia ficción, Costa Rica, polémica literaria.

KEY WORDS:

literary canon, literary field, science fiction, Costa Rica, literary polemic. 


\section{INTRODUCCIÓN}

La crítica histórica y literaria identifica uno de los momentos fundantes de la narrativa nacional costarricense en la polémica nacionalista, suscitada a partir de 1894 entre los escritores Ricardo Fernández Guardia y Carlos Gagini. Este estudiado hito llegó a problematizar un tópico a lo interno del ambiente literario local, a saber, la existencia de "héroes y viIlanos en la literatura costarricense" (Sánchez, 2003, p. 103) -no precisamente hablando de personajes literarios o funciones actanciales-.

La particularidad de estudiar polémicas literarias es que entran en juego dinámicas de poder, en muchas ocasiones tenidas por extraliterarias, en las que priman valores ideológicos y morales, más allá de los "puramente estéticos". Esto vendría a confirmar la existencia de una serie de aparatos institucionales con sus respectivas prácticas discursivas, que permean y en ocasiones determinan la realización de los discursos literarios (Trottier, 1993, p. 40) ${ }^{2}$.

Esto conduce inevitablemente a una distribución antagónica de posiciones, plasmada en discusiones en torno al "deber ser de la literatura". Esta no es ni mucho menos una característica intrínseca de la literatura costarricense, sino que responde a una configuración evidenciable en diversidad de áreas y disciplinas, esto es, lo que el sociólogo francés, Bourdieu, conceptualizó con el nombre de "campos".

Para Bourdieu, los campos son configuraciones que se presentan bajo "leyes generales" de estructuración para la confrontación; es decir, un espacio de lucha entre pretendientes y dominantes "cuyas formas específicas habrá que buscar cada vez, entre el recién llegado que trata de romper los cerrojos del derecho de entrada, y el dominante que trata de defender su monopolio y de excluir a la competencia" (2002, pp. 119-120). Desde esta perspectiva, la predeterminada separación entre teoría política y crítica literaria se estaría acortando, siendo que la subversión de la frontera que las separa pasa por entender que, las dimensiones que han sido tradicionalmente conocidas como privativas del lenguaje estético o literario pue-

2 La aproximación de este trabajo comparte el postulado de la sociología de la literatura bajo el cual, "el análisis científico de las condiciones sociales de producción y de la recepción de la obra de arte, lejos de reducirla o destruirla, intensifica la experiencia literaria" (Bourdieu, 1995, p. 15). den pasar a ser rasgos determinantes del lenguaje en general (Mouffe, 2007).

De esta manera, se puede estudiar una polémica que, en principio, parece partir desde la literatura (sobre qué debe escribirse, cómo escribirlo, con cuáles argumentos, etc.) para dar pie a una serie de argumentos extraliterarios (los intereses políticos de las instituciones literarias, la promoción solapada de valores neoliberales, etc.). En suma, estudiar una disputa dentro de un "campo literario" específico, prestando atención a sus actores (pretendientes y dominantes) y a sus respectivas estrategias discursivas.

Esto ya ha sido estudiado, aunque desde otras aristas, para la citada discusión de 1894 (Quesada, 1984; Rojas y Mondol, 2008; Sánchez, 2003). De aquella polémica fundacional resalta el hecho de que, lo que en principio parece ser una discusión respetuosa en torno a las vías que puede (o no) tomar una determinada práctica literaria, termina por convertirse en una contienda con tintes personalistas, agitaciones e incluso difamaciones de por medio.

De esta manera, el presente trabajo parte de los anteriores antecedentes y reflexiones para situar la polémica en torno a la producción literaria de ciencia ficción en Costa Rica, tomando como base las discusiones llevadas a cabo principalmente en el ámbito periodístico. Así, tiene por objeto el brindar una visión panorámica del debate que esta se estructura a través de un campo literario en disputa, es decir, a través de la lucha por el establecimiento de una determinada propuesta creativa; por la fijación de un canon literario para la ciencia ficción producida en el país ${ }^{3}$.

A continuación, en un primer momento, se dedica una sección para el repaso teórico sobre la conformación del canon en la literatura. Posteriormente, se ofrece una breve revisión de la historia y de lo que se ha entendido por literatura de ciencia ficción en Costa

3 Se hace la salvedad de que el artículo no busca establecer una "nueva visión poética" de la ciencia ficción costarricense. Su objetivo es menos pretencioso y en lugar de "repetir lo ya sabido", su aporte radica en las reflexiones que pueda suscitar en tanto plantea una exposición sistemática de los principales argumentos envueltos en la polémica, situándolo en una problemática teórica de mayor envergadura. Además de que, hasta la fecha, la polémica no ha sido abordada de manera pausada desde la crítica literaria. Por lo expuesto, se advierte al lector que el presente trabajo no apunta a inscribirse directamente como parte dentro de la polémica sino más bien estudiarla. 
Rica. El tercer acápite presenta el debate y hace referencia a los elementos principales presentes en la mencionada disputa.

\section{SOBRE LA CONFORMACIÓN DEL CANON LITERARIO}

La genealogía de lo que hoy se conoce bajo el nombre de canon, conduce ineludiblemente a ubicar su origen en el griego antiguo kanon, el cual posteriormente adoptado por el latín llegó a convertirse en sinónimo de "vara" o "regla"; es decir, fue empleada en principio como criterio de medición y sólo posteriormente vino a funcionar como criterio de valoración, llegando a traducirse hoy día en un singular tipo de norma o modelo a seguir (Reynolds y Wilson, 1986).

Aunque la concepción de canon en literatura ha variado según las épocas - esta ya era en la Antigüedad, una noción viva entre los copistas y filólogos de Alejandría- aquí interesa trabajar con la acepción más moderna del término. Por canon literario se entendería hoy, una lista de obras o autores, "constituida concretamente por las obras maestras o los autores más grandes [...] pero también obras que una comunidad considera valiosas, dignas de ser conservadas y comentadas" (Sullá, 2010, p. 139).

Por otra parte, Fokkema afirma que "un canon de literatura puede ser definido a grandes trazos como una selección de textos bien conocidos y prestigiosos, que son usados en la educación y que sirven de marco de referencia en el criticismo literario" (citado en López de Abiada, 1998b, p. 15). Esta última definición resulta de mayor peso, ya que ha sido tradicionalmente sobre la idea de "textos prestigiosos y selectos" sobre la cual se enzarza la polémica; porque después de todo, ¿quién decide cuáles textos tienen más valor que otros?

La discusión que ha girado en torno tanto a la formación, reproducción o asimilación del canon literario -como a su proyección particular bajo una forma antológica-, ha servido a lo largo del tiempo como catalizador de una serie de intensos debates a lo interno y externo de la crítica literaria. Su particular enfoque sobre los conjuntos textuales y su aceptación o rechazo proveniente de las instituciones literarias, tampoco ha dejado indiferente a los estudiosos de la historiografía literaria.

Se hace referencia primordialmente a una avanzada de estudios publicados a partir de la última década del siglo XX, en los que el establecimiento de un catálogo, lista o elenco de obras, que por su valor se vuelven merecedoras de ser leídas, conservadas y comentadas, se convierte en el centro de la discusión y que en la actualidad continúa generando calurosas contiendas en la academia y en las columnas de opinión.

La publicación del trabajo del crítico y teórico literario norteamericano Bloom titulado The Western Canon (1994) ocasionó la "desviación" de lo que se divisaba como problema central en aquella obra, provocando una disputa académica entre programas conservadores anglosajones y otros provenientes de enfoques "culturales" de tradición continental (Vera Méndez, 2005). En términos generales, en su libro, Bloom apostaba por la primacía del valor estético de la literatura ${ }^{4}$ frente a aspectos ideológicos, políticos, económicos o sociales. Esto provocó que el autor se ganara

[...] la censura y rechazo de la crítica neoestructuralista, y de autores y grupos feministas, homosexuales y multiculturalistas, porque el crítico norteamericano considera que ellos agregan a la experiencia literaria aspectos sociales, políticos, morales o de género que el propio autor no tiene interés en destacar. Con cierta acritud y humor negro Bloom, en El canon occidental denomina a estos ensayistas y críticos -encabezados por Jacques Lacan, Jacques Derrida, Roland Barthes o Michel Foucault- Escuela del Resentimiento, porque "Leer al servicio de cualquier ideología, a mi juicio, es lo mismo que no leer nada" (Bolaño, 2011, p. 26).

La cuestión anterior se torna más compleja sobre todo si se toma en cuenta que al intentar fijar "de una vez por todas" el canon de la literatura occidental, Bloom lo que hace es compilar autores y obras, adentrándose con esto en el delicado terreno de los gustos y las valoraciones. Entra en juego la forma

$4 \quad$ Muy en la línea de Sontag, en Contra la interpretación (1996). 
antológica como manera de canonizar; a fin de cuentas: "toda antología es un acto, fallido o no, de canonización" (Pozuelo y Aradra, 2000, p. 126).

La antología constituye así un producto en el que se ponen de manifiesto labores de selección destinadas a escoger "lo más representativo", ya sea de un autor, de un género o de un movimiento literario, es decir, hay una construcción canónica de consagración y legitimación en términos de inclusión y exclusión.

En contraste con la idea de privilegio, Mignolo (1991) dialoga con la necesidad de estudiar el canon literario con miras a reconocer la variada construcción de cánones destinados a satisfacer ciertos públicos. Para ello, elabora dos premisas por tener en cuenta a la hora de teorizar sobre el canon: 1) que "una de las funciones principales de la formación del canon (literarios o no) es asegurar la estabilidad y adaptabilidad de una determinada comunidad de creyentes"; $y$ 2) "cuando la formación del canon está relacionada con actividades disciplinarias [...] es esencial distinguir entre los aspectos vocacionales y los epistémi$\cos ^{\prime \prime}$ (Mignolo, 1998, p. 237).

Si se toman los conceptos anteriores ("comunidades de creyentes", "aspectos vocacionales y epistémi$\cos ^{\prime \prime}$ ) como instrumentos para desgranar las polémicas literarias, se verá que los mismos terminan por aparecer detrás de cada argumento que se plantea. En los acápites siguientes, se buscará demostrar cómo las reflexiones teóricas en torno a la forma antológica y el canon literario aquí establecidas, tienen una implicación en el debate sobre la llamada ciencia ficción costarricense.

\section{BREVE REPASO POR LA LITERATURA DE CIENCIA FICCIÓN EN COSTA RICA}

Umberto Eco (2014) afirma que la literatura de ciencia ficción siempre ha acarreado una vocación de termómetro social en las discusiones contemporáneas. El anterior postulado describe de manera más o menos exacta el problema que atañe al presente trabajo, y es que, el origen y evolución de lo que se ha reconocido como literatura de ciencia ficción en Costa Rica ha sido motivo tanto de promoción, de difusión y de estudio como de una creciente polémi- ca respecto a su naturaleza, primordialmente desde mediados de la década de los años noventa.

En 2010 el historiador cultural, Iván Molina, publicó un artículo fundamental desde el punto de vista de la historiografía literaria titulado "Género en construcción: la ciencia ficción costarricense". En este trabajo, el autor pretende registrar los antecedentes de la publicación de obras de dicho género en el país, y ubica sus primeras producciones hacia finales del siglo XIX ${ }^{5}$.

Además, Molina sitúa la novela El problema (1899) del guatemalteco Máximo Soto Hall como la primera en cultivar la ciencia ficción en Costa Rica, ya que ahí fue publicada. Además, cita también a La caída del águila (1920) de Carlos Gagini, a Dr. Kulmann (1926) de Ramón Junoy y al relato "El número 13013" (1925) de León Fernández Guardia, como primeras señales de la producción literaria circunscrita al género de ciencia ficción en el país (Molina, 2010, pp. 409-410) ${ }^{6}$.

En las décadas posteriores, y sobre todo a partir de mediados de la década de los sesenta, se comienza a dar una mayor producción de obras y publicaciones segregadas, aunque las "iniciativas en tal campo no dieron origen a un movimiento literario centrado en este género" (Molina, 2010, p. 410). Además, vale resaltar que otros autores han ubicado el relato "El planeta de los Perros" de Alberto Cañas, publicado en la Primera antología de la ciencia-ficción latinoamericana (1970), como el más representativo del género en la región centroamericana para la época (Molina Gavilán, 2007, p. 375). Pareciera que desde la publicación de la novela de Soto Hall y durante gran parte del siglo XX, la producción de ciencia ficción en Costa Rica no llegó a estructurarse como un género relativamente atrayente tanto para escritores como para lectores.

Varios autores ubican el inicio de la década de los noventa como una nueva era para la producción de ciencia ficción en Costa Rica (Molina, 2010; Molina

5 La aparición del género para esta época ya había sido adelantada por Flamarion Cardoso (2001).

6 Como se verá, proponer la inserción de narrativa de esta época dentro de los cánones de la ciencia ficción puede devenir problemático. Esta cuestión, naturalmente, formará parte de la polémica. 
Gavilán, 2007; Obando, 2013). De esta época destacan las publicaciones de Una sombra en el hielo (1995) de Laura Quijano Vincenzi en el campo de la novela y de la antología de relatos C.R. 2040 (1996). Esta última es de especial importancia, ya que por una parte presentó una serie de autores que seguirían en la órbita del género durante la década posterior, mientras que por otra llegó a potenciar el cultivo del género en Costa Rica, especialmente a través del formato antológico.

De manera reciente, en Costa Rica se ha venido dando una escalada ascendente en la producción del género sobre todo a través de novelas y antologías de relatos. A partir de la publicación de las antologías Posibles futuros (2009), Objeto no identificado y otros cuentos de ciencia ficción (2011), Lunas en vez de sombras y otros relatos de ciencia ficción (2013) y Te voy a recordar. Relatos de ciencia ficción (2015), puede evidenciarse un esfuerzo editorial continuo por posicionar el género en el país ${ }^{7}$. Con esto concuerda Roy Alfaro, quien asevera que la publicación de estas antologías ha aportado al "fenómeno de la denominada CF [ciencia ficción] costarricense [de] amplitud, legitimidad y divulgación" (2014, p. 132).

En síntesis, es posible señalar que durante las últimas dos décadas la producción, divulgación y consumo de literatura de ciencia ficción producida en Costa Rica ha venido aumentando y mostrando señales de querer posicionarse; esto mediante la considerable difusión de textos de narrativa claramente ubicables $^{8}$, aunado a la creciente edición de antologías de relato corto, que desde diversas temáticas y ángulos

$7 \quad$ Las cuatro antologías han sido publicadas por la Editorial de la Universidad Estatal a Distancia (EUNED), siendo la editorial que más ha apoyado la publicación de obras de ciencia ficción en el país (Molina, 2010: 409). Además, es de destacar el papel de la editorial independiente Club de Libros, la cual fomenta la producción de géneros no tradicionales como literatura infantil, fantástica, de terror, de autoayuda y de ciencia ficción. Se debe destacar que, en 2014 la Editorial Club de Libros publica una antología de relatos de la temática cyberpunk titulada Cyberpunk 506. A inicios de 2019, la Editorial Costa Rica publica la antología titulada Protocolo Roslin y otros relatos de ciencia ficción, conformada por ocho relatos de autores y autoras que en el pasado ya han participado en los compilados de la EUNED. Este acontecimiento sugiere una nueva etapa editorial para la narrativa corta de ciencia ficción en Costa Rica.

8 Se habla sobre todo de Señora del tiempo (2014) de Laura Quijano, publicada por Uruk Editores. La autora ha sido una constante del género en el país desde mediados de la década de los noventa. Señora del tiempo fue incluida en una lista de lecturas recomendadas por el Ministerio de Educación Pública para su estudio en secundaria. de abordaje exploran los vericuetos y desafíos de las sociedades postindustriales. En esta línea, para la primera década del dos mil, se señala un "salto cualitativo" de la literatura de ciencia ficción costarricense, en tanto se avanza más en la línea del tratamiento del lenguaje y de los espacios literarios (Pacheco, 2013, p. 65).

Por ello la literatura de ciencia ficción, en tanto ha intentado dar cuenta de los grandes retos del ser humano en su hacer cotidiano, sin dejar de lado sus grandes preocupaciones - a saber, la ecología, la ciencia, la sobrepoblación, los miedos, los retos, entre otrosse ha convertido hoy día en "tema importante dentro de la nueva literatura costarricense" (Alvarado, 2015, p. 2).

\section{UNA MIRADA AL DEBATE}

Tal y como se adelantaba en la introducción, no cabe duda de que una propuesta académica sobre cuestiones relativas al canon, puede en última instancia, funcionar como un detonante -para bien o mal- en la reflexión contemporánea sobre el quehacer tanto literario como disciplinario.

Desde su publicación en 2014, el artículo de Roy Alfaro ${ }^{9}$ presente en la Revista de Filología y Lingüística de la Universidad de Costa Rica (vol. 40, núm. 1) titulado "El novum en la ciencia ficción costarricense", ha desatado acalorados debates entre los círculos académicos, literarios y cibernéticos al menos en dos direcciones: 1) en lo referido al contenido y alcances de este "género en construcción", y 2) en torno al sentido de responsabilidad hacia lo interno de los cuerpos editoriales en las revistas académicas ${ }^{10}$.

Hay quienes le adjudican a la citada edición de la revista académica, un carácter de "parte aguas": en esta orientación, el también historiador, David Díaz

$9 \quad$ Alfaro es un investigador graduado de la Universidad de Costa Rica que ha dedicado gran parte de su obra académica a la crítica literaria y a la filosofía. De su vasta producción, el presente artículo se interesa más por la que se vincula directamente con la polémica, no obstante, cabe destacar su producción teórica que dialoga con los entrecruces de la filosofía y la ciencia ficción. A este respecto, véase Alfaro (2014e, 2014f, 2015d, 2016, 2017).

10 Antes de la publicación de este artículo que desencadena la polémica, hay un antecedente dedicado exclusivamente a la narrativa de ciencia ficción de Iván Molina en el que ya se vislumbran muchos de los elementos que se repetirán en "El novum en la ciencia ficción costarricense". Véase Alfaro (2013). 
(2015), argumenta que esta llegó a constituir un acontecimiento en sí mismo por abrir "quizás por primera vez en el país, la posibilidad de que este género literario fuera reconocido como tal por parte de una publicación académica de Costa Rica". Por otra parte, el artículo de Alfaro en la edición de la revista resulta relevante en tanto posiciona una discusión, la cual, examinada con mesura, llega a poner en cuestión la existencia de una práctica escritural del género en la historia literaria de Costa Rica, estableciendo la reflexión a partir de un canon extranjero ya establecido en Ciencia Ficción, como lo es el novum ${ }^{11}$.

A grandes rasgos, el detonante artículo de Alfaro propone la necesidad, dentro de la ciencia ficción, "de relacionar, en un proceso de acción recíproca, la tecnología con el novum. Es decir, no basta con creer (como afirma la PCFC) ${ }^{12}$ que la simple presencia de elementos tecnológicos en un cuento lo convierten en ciencia ficción" (2014b). El autor postula que lo que se ha denominado hasta el momento como ciencia ficción costarricense, no es tal, "sino que su visión reaccionaria le impide a esta plantear un mundo alternativo, un novum".

Dentro de su argumentación, Alfaro emprende contra la EUNED, contra el Grupo Nación e incluso contra Molina pues, a criterio del primero, estas entidades se "lanzan a la legitimación de los cuentos de Laura Casasa- [Núñez], Daniel Garro, Laura Quijano, etc., como autores de CF" (2014a, p. 132). Además, el autor establece una correlación entre la crisis financiera del año 2008 y el impulso editorial de la EUNED y afirma que "es un fenómeno ligado a la denominada Promoción de 1980 planteada por Quesada-Soto (2000) y que se caracteriza por sus vínculos con el neoliberalismo y el posmodernismo" (2014a, p. 133).

$\mathrm{Al}$ verse directamente aludido por Alfaro en su artículo académico, Molina responde meses después -en lo que sería la primera de varias réplicas posteriores- llegando a posicionar el debate a través de las páginas de opinión del periódico de circulación

11 El concepto de novum es tomado por Alfaro de Darko Suvin (1979). El mismo ha recibido diversas críticas por su carácter restrictivo (Freedman, 2000; Latham 2014).

12 Entiéndase "Pseudo-ciencia ficción costarricense", término utilizado por Alfaro y adaptado del propuesto por el afamado escritor Stanislaw Lem (1973). nacional La Nación con el artículo "El libre juego de la irracionalidad":

Aunque el artículo se presenta como un estudio académico, su objetivo fundamental es descalificar, en términos ideológicos, a los actuales escritores costarricenses de ciencia ficción (de Anacristina Rossi a Jessica Clark). A tales autores los define como neoliberales, antimarxistas y productores de una literatura de baja calidad, simplista y acrítica, cuyo propósito es adoctrinar a los jóvenes lectores a favor del neoliberalismo para cumplir así con los imperativos del Banco Mundial (...)[t]oda su argumentación se basa en palabras y frases descontextualizadas, a las que él les atribuye significados arbitrarios (...) al procedimiento de considerar como ciencia ficción legítima únicamente aquella que se ajusta a las características de la llamada "ciencia ficción dura" (es decir, la que prioriza los aspectos científicos y tecnológicos). Por otra parte, al descalificar la ciencia ficción que privilegia los temas sociales y culturales, Alfaro no solamente expone su profundo desconocimiento sobre el género, sino también acerca de lo que ha sido y es la ciencia ficción latinoamericana (Molina, 2014a).

Dos días después de la publicación de Molina aparece la contestación de Alfaro en La Nación: "Pseudociencia ficción costarricense". En este espacio, Alfaro retoma el planteamiento proveniente de su artículo académico sobre el novum aduciendo que debe existir una relación entre este concepto y la tecnología. Insiste en que el contexto del autor y el de su obra de ciencia ficción deben estar desligados totalmente. Menciona la obra Señora del tiempo, apuntando a su escasez de elementos pertenecientes al género. Afirma luego que "el problema, entonces, con la PCF no es que se ligue al neoliberalismo, sino que su visión reaccionaria le impide a esta plantear un mundo alternativo, un novum" (Alfaro, 2014b). Sin embargo, más adelante escribirá: "Guste a quien le guste, la PCFC no es más que una literatura panfletaria de carácter neoliberal, sin pies ni cabeza para llamarse ciencia ficción" (Alfaro, 2014b). Además, resiente el carácter personal que poseen los artículos de contraataque e invita a una reconstitución de las obras de la PCFC. En la argumentación, el autor termina lanzando la interrogante acerca de si el problema con las situaciones y lugares recurrentes en los 
textos de ciencia ficción costarricense tienen que ver con un tema de falta de talento.

Luego de esta réplica, presenta adicionalmente la "Respuesta a la Pseudo-ciencia ficción costarricen$\mathrm{se}^{\prime \prime}$ en noviembre del 2014. En este texto alude a la popularidad y polémica alrededor de su artículo publicado en la Revista de Filología y Lingüística. Dicha respuesta se publica en formato de "carta abierta" y tiene como objetivo insistir en que la crítica que rodea su trabajo ha creado falacias ad hominem en su contra, guiadas en parte por las percepciones de Molina. Seguidamente, el autor cita uno de los pasajes finales de la novela El problema de Soto Hall, la cual se ha catalogado como la obra inaugural de la ciencia ficción costarricense, para negar su relación con la ciencia ficción, luego de asociarla con una escena de la afamada saga Star Trek. Aquí también menciona que estas obras de CF tienen como blanco "un lector ideal caracterizado como estúpido" (Alfaro, 2014c):

Escritores que se han encasillado en querer atacarme y se les olvida que el golpe ha sido mortal. ¿Cómo se les ocurre plantear el viaje en el tiempo dentro de un esquema newtoniano, como en "Sputnik"? ${ }^{13}$ El viaje en el tiempo solo es posible dentro de un modelo, solamente teórico, desarrollado por Hawking. Con Newton y Einstein es imposible. Detalles como este y la inclusión ingenua y poco inteligente de recursos como las tablets $\mathrm{u}$ otras infelices ocurrencias desacreditan esta PCF. NO HAY CIENCIA FICCIÓN EN COSTA RICA [...] la PCF solo es vendible como CF dentro del concepto de un lector tan ignorante como el escritor que plantea tal literatura de tan mala calidad (Alfaro, 2014c).

Hacia finales de 2014, Alfaro publica otro artículo, ahora en torno a la mencionada novela de Laura Quijano, en Semanario Universidad, periódico de la Universidad de Costa Rica. En dicho texto comenta brevemente la obra de Quijano y algunos de los que considera sus defectos, los cuales se resumirían básicamente en la incapacidad de la autora de liberarse

13 Aquí hace referencia a uno de los relatos incluídos en la antología Posibles futuros (2009). de su contexto social y por el contrario "sacralizar de sobre manera el neoliberalismo" al no criticarlo y al "legitimar sus esquemas de socialización" (Alfaro, 2014d). Además, argumenta la falta de elementos futuristas basados en un amplio saber científico contemporáneo. La segunda parte de su artículo concierne a una acusación dirigida al Ministerio de Cultura y Juventud, el cual financia la escritura de la novela que luego será publicada por una editorial privada. También Alfaro se refiere a un artículo de La Nación en el cual, por causa de "apreciaciones intuitivas" se da el visto bueno a Señora del tiempo para ser una lectura recomendada por el Ministerio de Educación Pública.

Por otra parte, se publica en el mismo diciembre otro artículo de Alfaro titulado "Pseudo ciencia ficción y mediocridad" ahora en el diario La Prensa Libre. En este artículo se limita a reiterar las razones por las a su parecer, en Costa Rica no existe la ciencia ficción. Ahonda nuevamente en el desconocimiento de la ciencia y la tecnología, en la ausencia de diferencia entre el contexto del autor y el de su obra, en el sesgo neoliberal de los textos y en el supuesto pacto promocional que une al Estado y a los escritores. Finaliza brevemente reafirmando "la mediocridad de algunos académicos" que trabajan con intereses que apuntan a la política y hasta a la economía (Alfaro, 2015a).

A este debate se llegó a sumar desde otra arista el historiador David Díaz en el año 2015, quien en un artículo publicado en la revista digital Paquidermo argumentó:

[...] no puedo dejar pasar las limitantes del análisis de Alfaro y, especialmente, los profundos prejuicios de los que parte. Como científico social, me parece chabacano el intento de Alfaro por reducir los esfuerzos imaginativos y narrativos de los autores que critica a un lamentable discurso controlador de la labor de los escritores dentro de la sociedad y por identificarlos como ligados al (casi instrumentos del) pensamiento neoliberal (Díaz, 2015).

En el mismo artículo, Díaz identifica tres "prejuicios" de los que parte el texto de Alfaro: 1) 
los ecos de prejuicios imperiales, al prolongar la conceptualización restrictiva de Suvin y aplicarla para el caso costarricense; 2) el contexto manipulado, al vincular la aparición de las antologías de la EUNED con la crisis económica de 2008, y; 3) la influencia neoliberal, bajo la cual Alfaro estaría creando una conexión entre los escritores de ciencia ficción en Costa Rica y el Estado para la promoción de valores neoliberales. Los tres aglutinados para llegar a su conclusión:

La conexión neoliberal propuesta por Alfaro es irrespetuosa porque desprecia el trabajo de quienes producen ciencia ficción en el país a partir de supuestos no probados [...] un texto así, no se debió publicar, por lo menos en la forma en que apareció (Díaz, 2015).

De lo anterior se inspira Alfaro para publicar "Ciencia ficción o fantasía" en Semanario Universidad. Para inaugurar, cita dos definiciones de CF: la primera de Gomel quien se refiere a Suvin y su posición con respecto a la indispensabilidad del novum en la ciencia ficción, y la segunda de Spiegel quien corrobora la primera idea. Exige a Díaz la prueba de que él (Alfaro) "insulta y descalifica a personas e instituciones". Asevera, además, que su bibliografía no se reduce solamente a Suvin, pues cita incluso escritores de derecha. Por otra parte, indica que la "ciencia ficción a la tica" no es justificable bajo parámetros culturales, pues carece de "ciencia y tecnología futurista" (Alfaro, 2015b).

Un mes después, y para cerrar este recuento, este mismo articulista publica "Pseudo ciencia ficción y crítica literaria" también en el periódico Semanario Universidad, en donde afirma que desde la difusión de su artículo en la revista académica, se ha visto atacado por diferentes escritores. El autor atribuye esta reacción a que los autores costarricenses no están acostumbrados a la crítica, sino a un ambiente universitario condescendiente que se dedica a "endulzar" sus trabajos sin importar el resultado. Se trata, a su parecer, de una ayuda recíproca entre escritores y críticos, la cual posee supuestos intereses políticos para engañar al "lector o consumidor". Más adelante expresa: "Es espantoso ver a académicos creer, en una suerte de abominable falacia, que el pertenecer a la UCR [Universidad de Costa Rica], por ejemplo, es garantía de que su pensamiento está de por sí justificado y de que es científico" (2015c).

\section{¿UN CANON EN DISPUTA?}

En el segmento anterior se ha querido reproducir la discusión a manera de referencia para el lector. Es posible entrar ahora a su análisis desde varios aspectos relevantes que remiten a la formación y reproducción del canon como disputa dentro de un campo determinado. En primera instancia, es necesario apuntar que, en torno a la discusión canónica y a la forma antológica, la crítica literaria en muchos casos termina por concluir con la frase: "ésta no es mi antología". La posición de Alfaro lo sugiere al afirmar que "[...] el advenimiento de una CF bien definida a través de un novum, en Costa Rica, pasa por una renovación radical (tanto a nivel estilístico, como a nivel ideológico-cognoscitivo) de la Promoción de 1980" (Alfaro, 2014a, p. 38). Lo anterior conlleva a determinar que, como las antologías de ciencia ficción costarricense estudiadas por el autor no corresponden a la visión del novum, entonces ninguna de ellas puede ser su antología, o en su defecto, la antología de la ciencia ficción costarricense.

Si bien Vera Méndez (2005) asevera que "toda antología pretende erigirse como paradigma frente a otros modelos ya existentes", los procesos selectivos "vienen motivados fundamentalmente [...] no tanto para marginar formas culturales subalternas, sino para afirmar o negar aquellos modelos que son administrados por las instituciones literarias" (Vera Méndez, 2005, p. 5). La brecha que existe entre lo anterior y el criterio de Alfaro en torno el complot entre escritores y las instituciones estatales para fomentar el neoliberalismo es bastante distante, siendo que, a criterio de Molina, lo anterior se convierte en "una excusa teórica para darle apariencia académica a lo que, en el fondo, no es más que una descalificación ideológica indiscriminada de obras y autores" (2014b).

Este punto puede llegar a explicar la manera en que el corpus literario de la ciencia ficción ya no solo costarricense, sino también latinoamericana, "no obedece a los parámetros de la hard science fiction norteamericana, fundamentalmente de apoyatura en innovaciones científicas y descubrimientos y gadgets 
tecnológicos" (Ferrero, 2007, p. 133). De manera que cuando Alfaro habla de ciencia ficción, habla de una determinada ciencia ficción, una precisamente "suviniana"14.

Hay una valoración de la ciencia ficción producida en Costa Rica amparada en modelos considerados como "clásicos" dentro del género, en el sentido de argumentar, por ejemplo: a partir de la "perspectiva teórica suviniana que nos guía, en Costa Rica queda claro que no hay novum, luego la producción de Iván Molina- Jiménez, Jessica Clark, Laura Casasa-[Núñez], Daniel Garro, etc., no es CF [ciencia ficción]" (Alfaro, 2014, p. 137). Así, insistir que para que la literatura de ciencia ficción costarricense pueda ser aceptada como tal, esta deberá apegarse al concepto de novum. Esto podría repensarse sobre todo si se toma en cuenta que:

Muy pocos escritores hispanoamericanos han recibido el calificativo de autores de ciencia ficción (CF). La excepcionalidad de esta circunstancia no radica en la calidad de su obra ni en la cantidad de relatos representativos del género que hayan publicado. La condición implícita que parece exigírseles es la de haber recorrido territorios familiares para los aficionados a la CF, la mayoría de los cuales han formado sus expectativas en la lectura de obras de escritores estadounidenses y en la experiencia fílmica (Cano, 2004, p. 453).

En esta línea López Pellisa, refiriéndose a la antología Lunas en vez de sombras, certifica que: "Ios relatos de esta antología supeditan la tecnología a la temática social y emocional, asumiendo un contenido filosófico y de crítica social (...) que caracteriza, de algún modo, la mayoría de la producción de ciencia ficción latinoamericana" (2013, p. viii).

En síntesis, desde la visión de Alfaro difícilmente podrían abordarse variedades del género como la llamada "ciencia ficción feminista" característica del relato "Abel" en Lunas en vez de sombras, o bien,

14 En cuanto al debate hard/soft science fiction, Umberto Eco señala que la ciencia ficción, como literatura de consumo, no debe de ser juzgada (a no ser por un artificio esnobista) según los criterios aplicables a la literatura de experimento y de investigación (Eco, 2014: 412-413). las obras de la argentina Angélica Gorodischer o la cubana Daína Chaviano, dentro del contexto latinoamericano. Así, Juan Toledano (2009, p. x-xii) propone que la ciencia ficción cultivada en Costa Rica ha presentado dos tendencias marcadas: una más centroamericanista de tradición "postapocalíptica" y antiimperialista; y otra de tendencia localista. De lo anterior, se puede concluir que ni siquiera dentro del corpus costarricense del género existe una completa homogeneidad. A este respecto argumenta Haywood que:

La diversidad de América Latina necesariamente hace que haya muchas excepciones a cualquier generalización sobre la ciencia ficción latinoamericana, pero esto no anula el valor del intento de caracterizarla (...) [ya que] los autores latinoamericanos tienden a priorizar el tema de la posibilidad del acceso a la ciencia o a la tecnología, aunque esto no indique necesariamente una actitud tecnófila (2011, p. xiii).

Esta autora defiende la particularidad de la construcción latinoamericana de la ciencia ficción y plantea la dificultad de "adaptar sin adoptar", ya que es un género "cuyo origen y cuya tradición más fuerte se ubican en el Norte". Por este motivo, la ciencia ficción "ha sido un medio particularmente útil y pertinente para pensar la negociación entre centro y periferia, influencia y originalidad, y lo local y lo global en América Latina" (Haywood, 2011, p. ix).

\section{CONCLUSIONES}

Llegado a este punto, el lector podrá notar lo problemático del tema. El análisis del debate que atañe a este trabajo constata la existencia de juegos de poder que en última instancia permean la literatura. Se partió de los conceptos de campo literario y canon, para ejemplificar cómo tienen su asidero en una disputa específica que por sus dimensiones trasciende los límites estéticos esperados para una discusión en torno a géneros narrativos.

$\mathrm{Al}$ igual que la polémica fundacional de la literatura costarricense, en la estudiada aquí entran en juego aspectos extraliterarios que en suma se funden con 
debates normativos ${ }^{15}$. La discusión en torno lo que puede ser llamado (o no) "literatura costarricense" muta, entonces, hacia el terreno de la ciencia ficción. En esta circunstancia, las antologías que se han citado en este trabajo han jugado un papel trascendental, siendo que -más allá de la discusión normativa de los géneros temático-narrativos- su difusión ha acarreado la labor de presentarlas ante un público nacional como propuestas enmarcadas -bien o maldentro de la literatura de ciencia ficción.

En esta circunstancia, es válida la posibilidad de repensar el problema desde la experiencia de la lectura y la recepción (Jauss, 1965, 1975). Desde esta perspectiva, los argumentos planteados en la polémica, en última instancia terminarían por minar el sentido único de apropiación que se da en el encuentro entre el texto y sus lectores. Así, tanto la lectura direccionada presentada por la forma antológica, como el esencialismo genérico, tendrían una cuota de responsabilidad en modelar el "horizonte de expectativas". No obstante, pretender la causalidad entre lo anterior y el "horizonte de experiencias" exclusivo del lector, sería incurrir en un sesgo determinista.

Al revisar la disputa por canon literario en Costa Rica dentro de la reciente polémica alrededor de la ciencia ficción, la cual tuvo su momento más álgido entre los años 2014 y 2015, sale a la luz una interesante dependencia entre selección y discusión. La presentación de -hasta la fecha- la última de las antologías publicadas por la serie de la EUNED titulada Te voy a recordar. Relatos de ciencia ficción (2015), es redactada por Yolanda Molina Gavilán, quien afirma que:

Con su variedad estilística y temática, los ocho relatos incluidos en esta recopilación invitan al lector a hacer breves incursiones en diversos mundos fascinantes y en muchos casos extrañamente reconocibles. [...] Todo aficionado a la ciencia ficción de calidad disfrutará descubriendo en cada relato ese particular extrañamiento que Darko Suvin llamará el novum y que satisface la lógica narrativa propia del género. En definitiva, Te voy a recordar es una antología para recor-

15 El trabajo reciente de Muñoz (2017) aborda tangencialmente la polémica nacional alrededor de Cocorí (1947), de Joaquín Gutiérrez. Este caso ejemplifica de buena manera la relación entre la producción textual y las instituciones políticas. dar que la ciencia ficción costarricense sigue en auge y es merecedora de estudios críticos, traducciones a otros idiomas y aún mayor reconocimiento internacional (2015, p. xv).

No cabe duda de que con este fragmento la discusión se estaría complejizando aún más. ¿Influirá en la futura constitución de un nuevo canon de ciencia ficción costarricense? La utilidad del trabajo de Alfaro, aunque tal vez no sea su intención principal, es abrir el diálogo sobre lo que ha sido, es, y puede llegar a ser, la ciencia ficción costarricense.

En suma, y con miras al correcto análisis y disfrute del género de la ciencia ficción es imperativa la escisión entre los prejuicios y la crítica al incursionarse en la lectura y análisis de relatos nacionales, así como también el evitar medirlos con la vara de las creaciones norteamericanas y de las producciones cinematográficas convencionales. Aunque sea posible estudiar dicho género concebido desde distintas direcciones, estas deberían ser rehuidas para promover una visión integral que sea consciente del contexto y la ubicación espacio-temporal, propios de la época.

Sin más, este artículo pretende generar incentivos para la crítica y el análisis de textos de ciencia ficción producidos en Hispanoamérica, de manera que se pueda estimular una visión de conjunto en torno a características compartidas por distintas obras. Lo anterior contribuiría enormemente a reforzar las bases de una ciencia ficción que, incluso sin haber sido escrita en inglés, o en países del primer mundo, se logre definir e identificar dentro de sí misma.

\section{REFERENCIAS BIBLIOGRÁFICAS}

Alfaro, R. (2013). La ficción de Iván Molina Jiménez. Letras, 53, 201-217.

Alfaro, R. (2014a). El novum en la ciencia ficción costarricense. Revista de Filología y Lingüística de la Universidad de Costa Rica, 40(1), 129-140.

Alfaro, R. (2014b). Pseudo-ciencia ficción costarricense. La Nación. Disponible en: http://www. nacion.com/opinion/foros/Pseudo-ciencia-ficcioncostarricense_0_1447 255269.html (Acceso: 25.05.17). 
El campo literario de la ciencia ficción en Costa Rica: una mirada a la polémica por la fijación de su canon

Alfaro, R. (2014c). Respuesta a la pseudo-ciencia ficción (PCF) costarricense. Disponible en: https:// www.academia.edu/9993998/Respuesta_a_la_ pseudo-ciencia_ficci\%C3\%B3n_PCF_costarricense (Acceso: 25.05.17).

Alfaro, R. (2014d). El lado oscuro de Señora del Tiempo. Semanario Universidad. Disponible en: https:// semanariouniversidad.com/opinion/el-lado-oscuro-de-seora-del-tiempo/ (Acceso: 25.05.17).

Alfaro, R. (2014e). The Protos Mandate: ciencia ficción y neoliberalismo. Letras, 59, 77-97.

Alfaro, R. (2014f). Marxismo y ciencia ficción. Praxis. Revista de Filosofía, 72, 81-97.

Alfaro, R. (2015a). Pseudo ciencia ficción y mediocridad. La Prensa Libre. Disponible en: http://www. prensalibre.cr/Noticias/detalle/6647-pseudo-ciencia-ficcion-y-mediocridad (Acceso: 25.05.17).

Alfaro, R. (2015b). Ciencia ficción (CF) o fantasía. Semanario Universidad. Disponible en: https:// semanariouniversidad.com/opinion/ciencia-ficcincf-o-fantasa/ (Acceso: 23.05.17).

Alfaro, R. (2015c). Pseudo-ciencia ficción y crítica literaria (CL). Semanario Universidad. Disponible en: https://semanariouniversidad.com/opinion/ pseudo-ciencia-ficcin-pcf-y-crtica-literari a-cl/ (Acceso: 26.05.17).

Alfaro, R. (2015d). El novum tecnocrático. Hélice, 2(5), 6-20.

Alfaro, R. (2016). Las narrativas innaturales. Letras, 60, 185-212-

Alfaro, R. (2017). Ciencia ficción cuántica y la ontología del conjunto vacío. Praxis. Revista de Filosofía, 76(2), 91-106.

Alvarado, Ó. (2015). La literatura de ciencia ficción: una mirada al futuro en tiempo presente. Revista Humanidades, 5(2), 1-21.

Bloom, H. (2006). El canon occidental. Barcelona: Anagrama.
Bolaño, A. (2011). Cómo leer y por qué El canon occidental de Harold Bloom. Revista Amauta, 17(1), 25-50.

Bourdieu, P. (1995). Las reglas del arte. Génesis y estructura del campo literario. Barcelona: Anagrama.

Bourdieu, P. (2002). Campo de poder, campo intelectual. Buenos Aires: Editorial Montressor.

Cano, L. (2004). Angélica Gorodischer y Jorge Luis Borges: La Ciencia Ficción como parodia del canon. Hispania, 87(3), 453-463.

Cañas, A., Suárez, A., Menén, Á., Arango, Á., Olinto, A., Rebetez, R. (1970). Primera antología de la ciencia-ficción latinoamericana. Buenos Aires: Rodolfo Alonso Editor.

Casasa, L., Chamu, A., Clark, J., Díaz, D., Molina, I. y Quijano, L. (2009). Posibles futuros. Cuentos de ciencia ficción. San José: EUNED.

Castillo, M., Clark, J., Delgado, M., Garro, D., Molina, I., Ortiz, A., Ugalde, E. (2011). Objeto no identificado y otros cuentos de ciencia ficción. San José: EUNED.

Chaves, J. R., Clark, J., González, D., Lippi, E., Molina, I, Rossi, A. C. (2013). Lunas en vez de sombras y otros relatos de ciencia ficción. San José: EUNED.

Díaz, D. (2009). Imaginando un futuro incierto desde un pasado que se pierde. Acerca de los cuentos ticos de ciencia ficción de Iván Molina Jiménez. Revista Estudios, 22, 357-363.

Díaz, D. (2012). Viaje en el tiempo: el papel de la nostalgia en la ciencia-ficción de Iván Molina Jiménez. Istmo. Revista virtual de estudios literarios y culturales centroamericanos, $23 . \quad$ Disponible en: http://www.afehc-historia-centroamericana. org/?action=fi_aff\&id=3027 (Acceso: 03.06.17).

Díaz, D. (2015). Tres prejuicios sobre la ciencia ficción costarricense. Revista Paquidermo. Disponible en: http://www.revistapaquidermo.com/archives/11306 (Acceso: 19.06.17).

Eco, U. (2014). Apocalípticos e integrados. España: Penguin Random House. 
Fernández, N. (2008). El canon literario: un debate abierto. Per Abbat: Boletín filológico de actualización académica y didáctica, 7, 61-82.

Ferrero, A. (2007). La ciencia ficción y el canon literario hispanoamericano. Chasqui. Revista de Literatura Latinoamericana, 36(2), 132-134.

Fuentes, L., Garro, D., Herra, R., Molina, I., Pravisani, C., Quesada, U., Rossi, A. C. (2019). Protocolo Roslin y otros relatos de ciencia ficción. San José: Editorial Costa Rica.

Flamarion, C. (2001). La ciencia ficción, imaginario del siglo XX. En C. Flamarion (Ed.), Ensayos (pp. 119-196). San José: EUCR.

Freedman, C. (2000). Critical Theory and Science Fiction. Connecticut. Wesleyan University Press.

Gagini, C. (1973). La caída del águila. Editorial Costa Rica.

Haywood, R. (2011). Presentación. En VV. AA. Objeto No Identificado y otros cuentos de ciencia ficción. San José: EUNED.

Jauss, H. R. (1965/1975). La historia literaria como desafío a la ciencia literaria. En H. Gumbrecht (Comp.), La actual ciencia literaria alemana (pp. 37-114). Salamanca: Anaya.

Jauss, H. R. (1975/1987). El lector como instancia de una nueva historia de la literatura. En J. Mayoral (Comp.), Estética de la recepción (pp. 59-85). Madrid: Arco/Libros S.A.

Junoy, R. (2008). El Dr. Kulmann. San José: Editorial EUNED.

Latham, R. (2014). Introduction. En Rob Latham (Ed.), The Oxford Handbook of Science Fiction (pp. 1-22). Oxford: Oxford University Press.

Lem, S. (1973). On the Structural Analysis of Science Fiction. Science Fiction Studies, 1(1), 26-33.

López De Abiada, J. M. (1998a). De cánones literarios y antologías poéticas. Reflexiones sobre la última antología consultada. Actas del XIII Congreso de la Asociación Internacional de Hispanistas (pp. 655-661). Madrid: Editorial Castalia.
López De Abiada, J. M. (1998b). Lecciones sobre el canon literario. Reseñas Iberoamericanas. Literatura, sociedad, historia, 5(14), 15-26.

López Pellisa, T. (2013). Presentación. En J.R Chaves [y otros]. Lunas en vez de sombras y otros relatos de ciencia ficción (pp. VII-XI). San José: EUNED.

Mignolo, W. (1991). Teorizar a través de fronteras culturales. Revista de Crítica Literaria Latinoamericana, 17(33), 103-112.

Molina, I. (2010). Género en construcción: la ciencia ficción costarricense. A propósito de la novela El vuelo del Ra, de Manuel Delgado. A Contracorriente. A Journal on Social History and Literature in Latin America, 8(1), 408-415.

Molina, I. (2014a). El I i b r e juego de la irracionalidad. La Nación. Disponible en:http://www.nacion.com/opinion/ foros/libre-juego-irracionalidad_0_1446655328. html (Acceso: 22.05.17).

Molina, I. (2014b). Revistas académicas y responsabilidad universitaria. La Nación. Disponible en: http://www.nacion.com/opinion/foros/ Revistas-academicas-responsabilidad-universi taria_0_1453654628.html (Acceso: 22.05.17).

Molina Gavilán, Y. (2015). Presentación. En J. Clark [y otros]. Te voy a recordar. Relatos de ciencia ficción (pp. II-IV). San José: EUNED.

Molina Gavilán, Y. (2007). Chronology of Latin American Science Fiction, 1775-2005. Science Fiction Studies, 34, 369-431.

Mouffe, C. (2007). Prácticas artísticas y democracia agonística. Barcelona: Servei de Publicacions de la Universitat Autònoma de Barcelona.

Muñoz-Muñoz, M. (2017). Mujeres afrocostarricenses y multiculturalismo tardío: reforma de la Constitución de la República (blanca) de Costa Rica. América Latina Hoy, 77, 67-92.

Obando, A. (2013). ¿Objeto no identificado? (Parte I) La ciencia ficción en Costa Rica. Revista Paquidermo. Disponible en: http://www. 
El campo literario de la ciencia ficción en Costa Rica: una mirada a la polémica por la fijación de su canon

revistapaquidermo.com/archives/7881 (Acceso: 22.05.17).

Pacheco, C. (2013). Discursos literarios en Costa Rica. Revista ESPIGA, 27(1), 59-66.

Pozuelo Yvancos, J. M. y Aradra, R. (2000). Teoría del canon y literatura española. Madrid: Cátedra.

Quesada, Á. (1984). Reflexiones acerca de la polémica sobre nacionalismo literario. Revista de Filología y Lingüística, 10(2), 3-13.

Quijano, L. (2014). Señora del tiempo. San José: Uruk Editores.

Reynolds, L. y Wilson, N. (1986). Copistas y filólogos. Las vías de transmisión de las literaturas griega y latina. Madrid: Editorial Gredos.

Rojas, J. P. y Mondol, M. (2008). La Venus de Milo frente a la India de Pacaca: discursividad fundante de la literatura costarricense. Káñina. Revista de Artes y Letras, 32(1), 97-109.

Rossi, A. C., Garro, D., González, D., Molina, I., Clark, J., Quijano, L., Quesada, U. (2015). Te voy a recordar. Relatos de ciencia ficción. San José: EUNED.

Sánchez, A. (2003). El modernismo contra la nación. La polémica literaria de 1894 en Costa Rica. Revista de Filología y Lingüística, 29(1), 103-117.

Sontag, S. (1996). Contra la interpretación. Madrid: Alfaguara.

Soto Hall, M. (1992). El problema. San José: Editorial Universidad de Costa Rica.

Sullá, E. (1998). El debate sobre el canon literario. En E. Sullá (comp.), El canon literario (pp. 11-36). Madrid: Arco/Libros.

Sullá, E. (2009). Canon y clásico. Deslindes terminológicos. En M. Llombart (Ed.), Traversée. Hommage à Montserrat Prudon (pp. 87-92). Paris: Editions CaIliopées.

Sullá, E. (2010). Canon literario y humanismo. En P. Aullón (Coord.), Teoría del Humanismo (pp. 139165). Madrid: Verbum.
Suvin, D. (1979). Metamorphoses of Science Fiction. On the Poetics and History of a Literary Genre. New Haven and Londres: Yale University Press.

Trottier, D. (1993). Juego textual y profanación: análisis sociocrítico de Lázaro de Betania de Roberto Brenes Mesén. San José: EUCR.

Vera Méndez, J. D. (2005). Sobre la forma antológica y el canon literario. Espéculo. Revista de estudios literarios. Universidad Complutense de Madrid. Disponible en http://www.ucm.es/info/especulo/ numero30/antcanon.html. 